\title{
A prospective study of hepatitis B virus markers in patients with chronic HBV infection from Brazilian families of Western and Asian origin
}

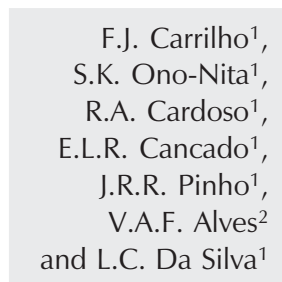

Correspondence

\section{F.J. Carrilho}

R. Silva Correia, 153, Apto. 41 04537-040 São Paulo, SP

\section{Brasil}

Fax: +55-11-3063-1559

E-mail: fjcarril@usp.br

Research supported in part by FINEP and Alves de Queiróz Family Fund for Research.

Publication supported by FAPESP.

Received July 16, 2004 Accepted April 26, 2005
1Setor de Hepatologia, Departamento de Gastroenterologia, 2Departamento de Patologia, Faculdade de Medicina, Universidade de São Paulo, São Paulo, SP, Brasil

\section{Abstract}

The purpose of the present study was to determine the frequency of hepatitis B virus (HBV) markers in families of HBsAg-positive patients with chronic liver disease. Serum anti-HBc, HBsAg and antiHBs were determined by enzyme immunoassay and four subpopulations were considered: genetically related (consanguineous) and nongenetically related (non-consanguineous) Asian subjects and genetically related and non-genetically related Western subjects. A total of 165 and 186 relatives of Asian and Western origin were enrolled, respectively. The occurrence of $\mathrm{HBsAg}$ and anti-HBs antibodies was significantly higher $(\mathrm{P}<0.0001)$ in family members of Asian origin $(81.8 \%)$ than in family members of Western origin $(36.5 \%)$. HBsAg was also more frequent among brothers $(79.6$ vs $8.5 \%$; $\mathrm{P}<0.0001)$, children (37.9 vs 3.3\%; $\mathrm{P}<0.0001)$ and other family members $(33.9$ vs $16.7 \%$; $\mathrm{P}<0.0007)$ of Asian than Western origin, respectivelly. No difference between groups was found for anti-HBs, which was more frequently observed in fathers, spouses and other non-genetic relatives. HBV infection was significantly higher in children of Asian than Western mothers $(P<0.0004)$. In both ethnic groups, the mothers contributed more to their children's infection than the fathers $(\mathrm{P}<$ 0.0001). Furthermore, HBsAg was more frequent among consanguineous members and anti-HBs among non-consanguineous members. These results suggest the occurrence of vertical transmission of HBV among consanguineous members and probably horizontal sexual transmission among non-consanguineous members of a family cluster. Thus, the high occurrence of dissemination of HBV infection characterizes family members as a high-risk group that calls for immunoprophylaxis. Finally, the study showed a high familial aggregation rate for both ethnic groups, 18/19 (94.7\%) and 23/26 (88.5\%) of the Asian and Western origin, respectively.
Key words - Hepatitis B

- Familial clustering

- HBsAg

- Vertical transmission

- Anti-HBc

- Anti-HBs 


\section{Introduction}

Several sero-epidemiological studies on the general and blood-donor populations have identified asymptomatic carriers of the viral surface antigen of hepatitis B (HBsAg). Upon investigation, a significant proportion of those individuals turned out to have some liver injury ranging from minor alterations to chronic active hepatitis, liver cirrhosis and hepatocellular carcinoma (1). Human chronic hepatitis B virus (HBV) infection is frequent in certain regions of the world, where the prevalence of HBV carriers in the general population is high (2).

In Brazil, studies on HBsAg prevalence were carried out in the general population, but mainly in volunteer candidates for blood donation (1). The observed prevalence was $0.3 \%$ in the South of the country and $11.3 \%$ in the Amazon region (1). For the State of São Paulo, about $1.0 \%$ was found in the capital and 0.3 to $1.3 \%$ in the interior of the state (1).

The prevalence of asymptomatic carriers varies among countries, ranging from low (0.1-2.0\%) to medium (2.0-7.0\%) and high (8.0-20.0\%) (2). As discussed below, this prevalence also varies within countries from region to region, depending on different factors, such as socioeconomic conditions, the extent of drug addiction, the extent of alcoholism, professional blood donation, homosexual behavior, and there is also a high familial incidence (3).

The familial occurrence of the HBV infection has been well established for some ethnic groups. Initially, Ohbayashi et al. (4) reported 3 Japanese families in which 36 of the 54 members were $\mathrm{HBsAg}$ positive. Of these, some were healthy carriers while others had liver cirrhosis and hepatocellular carcinoma. Similar observations have been reported for the American (5), European (6) and Asian continents $(7,8)$. However, there are few comparisons among populations of different ethnic backgrounds living in the same country $(8,9)$.

Recently, we showed that family members and household contacts of chronic HBV carriers are at high risk to acquire hepatitis B in an area of low hepatitis B prevalence (10).

In view of the need to obtain more information about the familial occurrence of HBV in Brazil and to compare it among different ethnic groups, the purpose of this study was to prospectively determine the familial aggregation, HBV markers in the progeny of infected mothers and fathers, and the frequency and analysis of variance of HBV markers per ethnic group and degree of familial relation.

\section{Material and Methods}

\section{Patients}

Nineteen patients of Japanese background and 26 of Western origin were attended at the Hepatology Branch, Discipline of Clinical Gastroenterology, University of São Paulo School of Medicine. These patients were considered to be the probands (index cases) and after their first visit their relatives were prospectively studied as two groups in terms of familial relation, i.e., i) genetically related persons consisting of consanguineous individuals (parents, brothers, sisters, sons, daughters, grandparents, aunts, uncles, cousins, nieces, and nephews), and ii) nongenetically related persons consisting of nonconsanguineous individuals (husbands, wives, brothers-in-law, sisters-in-law, and others that could directly or indirectly be in contact with the family). A total of 165 relatives of Asian (Japanese) background and 186 of Western origin were enrolled after being invited and giving informed consent to participate in the study.

\section{Inclusion criteria}

Probands were $\mathrm{HBsAg}$-seropositive individuals with chronic liver disease such as 
chronic hepatitis, liver cirrhosis and hepatocellular carcinoma, diagnosed by liver biopsy. The parents of the probands belonged to the same ethnic group. Children of mixed marriages were not included in the study.

\section{Methods}

All study procedures were approved by the institutional review board of the Department of Gastroenterology, University of São Paulo School of Medicine, São Paulo, SP, Brazil.

Seroimmunologic markers for present (anti-HBc and $\mathrm{HBsAg}$ ) and past (anti-HBc and anti-HBs) HBV infection were searched for in the relatives of the index cases.

\section{Identification}

For each index case and respective relatives, the parameters age, sex, ethnic origin, and degree of familial relation were evaluated.

HBsAg, anti-HBc and anti-HBs determination

The presence of anti-HBc, HBsAg and anti-HBs in serum was determined by the enzyme immunoassays provided by Abbott Laboratories (North Chicago, IL, USA), with a sensitivity, specificity and reproducibility of 100, 95 and $100 \%$ for Corzyme, of 100 , 100 and $100 \%$ for Auszyme II, and of 100, 100 and $100 \%$ for Ausab, respectively (11).

\section{Statistical analysis}

The mean age of probands in both ethnic groups (Asian and Western) was compared by the $t$-test and categorical variables were compared by the chi-square or Fisher exact test. The influence of origin (Asian and Western) and degree of familial relation (genetic and non-genetic) on the serum immunologic markers was evaluated by linear model methods as reported by Grizzle et al. (12) and Koch et al. (13). Four subpopula- tions were considered on the basis of ethnic group and degree of familial relation (Asian, genetically related; Asian, non-genetically related; Western, genetically related; Western non-genetically related). The results of the HBV serum markers were considered to be the response variable (HBsAg, anti-HBs and negative). The calculations were made using the SAS System according to the CATMOD procedure (14).

\section{Results}

\section{Index cases}

Nineteen patients of Asian origin and 26 of Western origin were the probands, who did not differ significantly in terms of gender (11 males/8 females and 21 males/5 females, respectively; $\mathrm{P}=0.0945$ ) or mean age $(39.8 \pm 11.3(19-63)$ and $34.5 \pm 17.3(7-$ $61)$ years old, respectively $(\mathrm{P}>0.05)$.

\section{Familial HBV markers}

Serum samples from relatives were first screened for hepatitis B infection and subjects positive for anti-HBc were selected.

\section{HBsAg and anti-HBs}

The overall frequency of both HBsAg and anti-HBs was $135 / 165(81.8 \%)$ for relatives of Asian origin and 68/186 (36.5\%) for relatives of Western origin $(\mathrm{P}<0.0001)$. Significant differences in 106/134 (79.1\%) and 38/143 (26.5\%) were also observed between the brothers and sisters $(\mathrm{P}<0.0001)$, sons and daughters $(\mathrm{P}<0.0001)$ and other relatives $(\mathrm{P}<$ 0.0007 ) of the two groups (Asian and Western), as shown in Table 1. In contrast, among the parents of the probands the difference in $17 / 17(100 \%)$ and 17/23 (73.9\%), respectively, of Asian and Western origin, only tended to be significant $(\mathrm{P}=0.0578)$. The small number of cases of fathers and mothers of the index cases was compensated for with the inclusion 
of other parents belonging to the same kinship.

\section{HBsAg}

A significant difference $(\mathrm{P}=0.0001)$ in the frequency of HBsAg was detected between Asian relatives, 79/165 (47.9\%), and Western relatives, 10/186 (10.7\%). Concerning the degree of familial relation, there was a significant difference between the two groups regarding the mothers, brothers and sisters and sons and daughters.

\section{Anti-HBs}

The anti-HBs frequency found for the Asian relatives was 56/165 (33.9\%) and did not differ significantly $(\mathrm{P}=0.1209)$ from that of the Western group, 48/186 (25.8\%). Regarding the degree of familial relation, a significant difference was observed only for the parents and other family relatives.

\section{Frequency of familial aggregation rate per ethnic group}

The familial aggregation frequency, given by the number of families having at least one HBsAg- or anti-HBs-positive member (except the index case) in relation to the total number of families studied, was 94.7 and $88.5 \%$ for the Asian and Western groups, respectively $(\mathrm{P}=0.4319$; Table 2$)$.

\section{$\mathrm{HBV}$ markers in the progeny of $\mathrm{HBsAg}$ - positive mothers}

The progeny of 16 mothers of Asian origin and 7 of Western origin was studied (Table 3); of the 67 subjects of Asian origin, $56(83.6 \%)$ presented HBsAg and $5(7.5 \%)$ anti-HBs, whereas of the 20 subjects of Western origin, only 8 (40\%) presented HBsAg and $4(20.8 \%)$ anti-HBs $(\mathrm{P}=0.0004)$.

\section{$\mathrm{HBV}$ markers in the progeny of $\mathrm{HBsAg}$ - positive fathers}

Ten fathers of Asian origin and 20 of Western origin were enrolled in the study (Table 4). Of the 30 subjects of the Asian progeny, 7 (23.3\%) were HBsAg positive and $7(23.3 \%)$ anti-HBs positive. For the 69 Western descendents, the markers were de-

\begin{tabular}{|c|c|c|c|c|c|c|c|c|}
\hline \multirow[b]{3}{*}{ Family members } & \multicolumn{8}{|c|}{ Ethnic groups } \\
\hline & \multicolumn{3}{|c|}{ Asian origin } & \multicolumn{3}{|c|}{ Western origin } & \multirow[b]{2}{*}{$\chi^{2}$} & \multirow[b]{2}{*}{$\mathrm{P}$} \\
\hline & $\begin{array}{l}\text { HBsAg } \\
\mathrm{N}(\%)\end{array}$ & $\begin{array}{c}\text { Anti-HBs } \\
\mathrm{N}(\%)\end{array}$ & $\begin{array}{c}\text { Negative } \\
\mathrm{N}(\%)\end{array}$ & $\begin{array}{l}\mathrm{HBsAg} \\
\mathrm{N}(\%)\end{array}$ & $\begin{array}{c}\text { Anti-HBs } \\
\mathrm{N}(\%)\end{array}$ & $\begin{array}{c}\text { Negative } \\
N(\%)\end{array}$ & & \\
\hline Immediate & $9(52.9)$ & $8(47.1)$ & 0 & $7(30.4)$ & $10(43.5)$ & $6(26.1)$ & 5.70 & 0.0578 \\
\hline Mothers & $9(90.0)$ & $1(10.0)$ & 0 & $4(30.7)$ & $6(46.2)$ & $3(23.1)$ & - & - \\
\hline Fathers & 0 & $7(100.0)$ & 0 & $3(30.0)$ & $4(40.0)$ & $3(30.0)$ & - & - \\
\hline Brothers and sisters & 39 (79.6) & $10(20.4)$ & 0 & $4(8.5)$ & $10(21.3)$ & $33(70.2)$ & 61.47 & $<0.0001$ \\
\hline Sons and daughters & 11 (37.9) & $1(3.5)$ & $17(58.6)$ & $2(3.3)$ & $7(11.7)$ & $51(85.0)$ & 19.27 & $<0.0001$ \\
\hline Spouses & $1(7.1)$ & $11(78.6)$ & $2(14.3)$ & $1(5.0)$ & $14(70.0)$ & $5(25.0)$ & 0.61 & 0.7387 \\
\hline Other relatives & 19 (33.9) & $26(46.4)$ & $11(19.7)$ & $6(16.7)$ & $9(25.0)$ & $21(58.3)$ & 14.48 & $<0.0007$ \\
\hline Total & 79 (47.9) & $56(33.9)$ & $30(18.2)$ & $20(10.7)$ & $48(25.8)$ & $118(63.5)$ & 87.16 & $<0.0001$ \\
\hline
\end{tabular}

The numbers within parentheses are percent, with the total being $100 \%$ for each ethnic group: Asian $(\mathrm{N}=165)$ and Western (N = 186). The probands were 19 patients of Asian origin and 26 of Western origin. For detailed explanation of statistical analysis (chi-square test), see Results section. 
tected in $8(11.6 \%)$ and $6(8.7 \%)$ members, respectively $(\mathrm{P}=0.0255)$.

\section{HBV markers in progeny from fathers or mothers (HBsAg) of Asian origin}

Nine HBsAg-positive fathers and 15 HBsAg-positive mothers with a 26- and 63member progeny, respectively, were enrolled in this investigation. HBsAg was detected in $3(11.6 \%)$ and anti-HBs in $7(26.9 \%)$ members of the first group, while for the second group, $52(82.6 \%)$ were found to be HBsAg positive and $5(7.9 \%)$ anti-HBs positive, with a significant difference between groups $(\mathrm{P}<0.0001)$. The results for one family were excluded from the analysis because both father and mother were HBsAg positive.

\section{HBV markers in progeny from fathers or} mothers (HBsAg) of Western origin

Eighteen HBsAg-positive fathers with a progeny of 64 children and 5 mothers with a progeny of 15 children were studied. HBsAg was detected in $7(10.9 \%)$ and anti-HBs in 6 (9.4\%) of the 64 descendants of the first group, while for the 15 descendants of the second group, HBsAg was found in $7(46.6 \%)$ and anti-HBs in $4(26.7 \%)$ individuals $(\mathrm{P}=$ 0.0002). The results for two families were excluded from the analysis because both father and mother were HBsAg positive.

Frequency of $\mathrm{HBV}$ markers in the progeny of fathers or mothers (HBsAg) of Asian and Western origin

Progenies consisting of 90 and 78 individuals from 27 fathers and $20 \mathrm{HBsAg}$-positive mothers, respectively, were investigated. HBsAg was detected in 10 individuals $(11.1 \%)$ and anti-HBs in $13(14.4 \%)$ individuals in the first group, whereas in the second group the frequency found for these markers was $75.7 \%$ (59/78) and $11.5 \%$ (9/ $78)$, respectively $(\mathrm{P}=0.0001)$.

Frequency of HBV markers per ethnic group and degree of familial relation

The frequency of HBV markers according to ethnic origin (Asian and Western) and the degree of familial relation (genetic and non-genetic) were compared and are presented in Table 5. Analysis of variance

Table 2. Frequency of familial aggregation rate with past or present hepatitis B virus infection as a function of ethnic group.

\begin{tabular}{|c|c|c|}
\hline & \multicolumn{2}{|c|}{ Ethnic group } \\
\hline & Asian origin & Western origin \\
\hline No. of families studied & 19 & 26 \\
\hline Familial aggregation rate - $\mathrm{N}(\%)$ & $18(94.7)$ & $23(88.5)$ \\
\hline P level (Fisher exact test) & \multicolumn{2}{|c|}{0.4319} \\
\hline
\end{tabular}

Table 3. Frequency of hepatitis B virus (HBV) markers in the progeny of HBsAgpositive mothers.

\begin{tabular}{lcc}
\hline & \multicolumn{2}{c}{ Ethnic group } \\
\cline { 2 - 3 } & Asian origin & Western origin \\
\hline HBsAg (+) mothers (N) & 16 & 7 \\
Total number of children & 67 & 20 \\
HBsAg - N (\%) & $56(83.6)$ & $8(40.0)$ \\
Anti-HBs - N (\%) & $5(7.5)$ & $4(20.0)$ \\
HBV-negative markers - N (\%) & $6(9.5)$ & $8(40.0)$ \\
\hline
\end{tabular}

$\mathrm{P}=0.0004$ and $\chi^{2}=15.54$ when HBsAg and anti-HBs frequency in 67 Asian and 20 Western origin children were compared.

Table 4. Frequency of hepatitis B virus (HBV) markers in the progeny of HBsAgpositive fathers.

\begin{tabular}{lcc}
\hline & \multicolumn{2}{c}{ Ethnic group } \\
\cline { 2 - 3 } & Asian origin & Western origin \\
\hline HBsAg (+) fathers (N) & 10 & 20 \\
Total number of children & 30 & 69 \\
HBsAg - N (\%) & $7(23.3)$ & $8(11.6)$ \\
Anti-HBs - N (\%) & $7(23.3)$ & $6(8.7)$ \\
HBV-negative markers - N (\%) & $16(53.4)$ & $55(79.7)$ \\
\hline P $=0.0255$ and $\chi^{2}=7.34$ when HBsAg and anti-HBs frequency in 30 Asian and 69 \\
Western origin children were compared.
\end{tabular}


Table 5. Frequency and analysis of variance of hepatitis B virus (HBV) markers per ethnic group and degree of familial relation.

\begin{tabular}{llcrrr}
\hline Ethnic group & Degree of family relatedness & $\begin{array}{c}\mathrm{HBsAg} \\
(\mathrm{N})\end{array}$ & $\begin{array}{c}\text { Anti-HBs } \\
(\mathrm{N})\end{array}$ & $\begin{array}{r}\text { HBV-negative } \\
\text { markers (N) }\end{array}$ & $\begin{array}{r}\text { Total } \\
(\mathrm{N})\end{array}$ \\
\hline \multirow{2}{*}{ Asian origin } & Genetically related (consanguineous) & 76 & 28 & 22 & 126 \\
& Non-genetically related (non-consanguineous) & 3 & 28 & 8 & 39 \\
& & & & 105 & 154 \\
Western origin & Genetically related (consanguineous) & 19 & 30 & 10 & 31
\end{tabular}

Intercept: 2 degrees of freedom; $\chi^{2}=20.39 ; \mathrm{P}=0.0001$. Ethnic group: 2 degrees of freedom; $\chi^{2}=71.15 ; \mathrm{P}=$ 0.0001 . Degree of familial relation: 2 degrees of freedom; $\chi^{2}=45.46 ; P=0.0001$. Residual: 2 degrees of freedom; $\chi^{2}=2.71 ; P=0.2580$.

Table 6. Frequency of hepatitis B virus (HBV) markers per ethnic group and degree of familial relation.

\begin{tabular}{|c|c|c|c|c|c|c|}
\hline \multirow[b]{2}{*}{ Ethnic group } & \multirow[b]{2}{*}{$\begin{array}{l}\text { Degree of family } \\
\text { relatedness }\end{array}$} & \multirow[b]{2}{*}{$\begin{array}{l}\mathrm{HBV} \\
\text { markers }\end{array}$} & \multicolumn{2}{|c|}{ Observed } & \multicolumn{2}{|c|}{ Predicted } \\
\hline & & & Probability & $\begin{array}{l}\text { Standard } \\
\text { error }\end{array}$ & Probability & $\begin{array}{c}\text { Standard } \\
\text { error }\end{array}$ \\
\hline \multirow[t]{6}{*}{ Asian origin } & \multirow{3}{*}{$\begin{array}{l}\text { Genetically related } \\
\text { (consanguineous) }\end{array}$} & $\mathrm{HBsAg}$ & 0.60 & 0.04 & 0.60 & 0.04 \\
\hline & & Anti-HBs & 0.22 & 0.04 & 0.21 & 0.03 \\
\hline & & Negative & 0.17 & 0.03 & 0.19 & 0.03 \\
\hline & \multirow{3}{*}{$\begin{array}{l}\text { Non-genetically related } \\
\text { (non-consanguineous) }\end{array}$} & $\mathrm{HBsAg}$ & 0.08 & 0.04 & 0.10 & 0.04 \\
\hline & & Anti-HBs & 0.72 & 0.07 & 0.75 & 0.06 \\
\hline & & Negative & 0.20 & 0.06 & 0.15 & 0.04 \\
\hline \multirow[t]{6}{*}{ Western origin } & \multirow{3}{*}{$\begin{array}{l}\text { Genetically related } \\
\text { (consanguineous) }\end{array}$} & $\mathrm{HBsAg}$ & 0.12 & 0.03 & 0.13 & 0.03 \\
\hline & & Anti-HBs & 0.19 & 0.03 & 0.21 & 0.03 \\
\hline & & Negative & 0.68 & 0.04 & 0.67 & 0.04 \\
\hline & \multirow{3}{*}{$\begin{array}{l}\text { Non-genetically related } \\
\text { (non-consanguineous) }\end{array}$} & $\mathrm{HBsAg}$ & 0.03 & 0.03 & 0.02 & 0.01 \\
\hline & & Anti-HBs & 0.64 & 0.09 & 0.58 & 0.07 \\
\hline & & Negative & 0.32 & 0.08 & 0.40 & 0.07 \\
\hline
\end{tabular}

showed a significant difference in both comparisons. Since the interaction between ethnic group and familial relation was not significant, the model was adjusted taking into consideration only the main effects. Finally, analysis of categorical data showed full agreement between the observed and expected probabilities (Table 6).

\section{Discussion}

Families represent an excellent model for the study of qualitative and quantitative features concerning host response to certain etiologic agents and transmission mechanisms through people exposed to a variety of environmental characteristics. Family studies have proved to be important for obtaining information about viral hepatitis $B$, which shows few clinical symptoms but a clear trend to chronicity (5).

The mechanisms of hepatitis B transmission are not fully understood, but they seem to involve several aspects and the genetic component, in particular, is still being debated (15-17). 
Despite all of these unclear features, few worldwide large-scale studies are available, including geographic areas of low and high incidence of HBV infection. Numerous reports of families with multiple cases of acute and chronic hepatitis B $(5,18,19)$ have confirmed the possibility of familial clustering. However, they are of little value for estimating the frequency of these events in the population and for the understanding of certain aspects of HBV familial clustering (20).

On the basis of information from outside Brazil (6) and of preliminary Brazilian data (1) about relatives of HBV-positive patients with liver disease, two populations of distinct ethnic origins are described in the present report, i.e., the relatives of Brazilian probands of Asian and Western origin. The choice was based on the fact that immigrants of these two ethnic groups correspond to a relatively large proportion of the population of the State of São Paulo. In fact, São Paulo contains the largest Japanese descendant population after Japan.

Indeed, one of the main objectives of the present study was to determine whether our data are similar to those reported by others in the literature $(4,5,20-22)$.

Concerning the inclusion criteria, it is worth mentioning work by other investigators. Bruguera et al. (21) studied 100 relatives of 29 patients with chronic HBV-related liver disease admitted to the Hospital of the University of Barcelona. HBsAg was detected in 12 members of the families studied and, of these, 8 were asymptomatic HBV carriers, 1 had cirrhosis and 3 progressed to acute hepatitis. There was no report of parenteral exposure among the familial contacts. The HBsAg frequency $(12.0 \%)$ in the families was considerably higher than the prevalence of the antigen in patients $(0.3 \%)$ without liver disease and in volunteer blood donors $(0.4 \%)$.

The same group from Barcelona (20) published a study of familial contacts of probands with acute hepatitis and chronic hepatitis and healthy HBV carriers, and de- termined the occurrence of HBsAg and antiHBs compared to volunteer blood donors. The prevalence of these markers was significantly higher among the 178 relatives (39.2\%) with domestic contact with the 54 HBsAg carriers than in the control group of 834 blood donors $(12.1 \%$; $\mathrm{P}<0.001)$. The authors concluded that the risk of acquiring HBV infection for the relatives of patients with some HBV-related liver disease (acute $=33.0 \%$; chronic $=46.3 \%$ ) was higher than for individuals with no familial case of liver disorders $(13.4 \%$; $\mathrm{P}<0.01)$. Similar data were reported by others $(5,22)$.

Due to the relevance of these results and the ease to study patients with chronic liver diseases compared to patients with the acute forms, the families of the chronic cases were given priority in this study. The existence of a member with a chronic form of liver disease greatly motivates the family to join the study (Carrilho FJ and Da Silva LC, unpublished data).

Searching for HBsAg and anti-HBs has been generally adopted to detect present or past HBV infection (23). Anti-HBc is also another widely used marker of HBV infection (9).

The probands of Asian and Western origin were not significantly different regarding age and gender. The present study showed that the general occurrence of the HBsAg and anti-HBs markers, which indicate HBV contact, was $81.8 \%$ for the Asian families and $36.5 \%$ for the Western families (Table $1)$. This difference in the percent of members of a group who are HBsAg and antiHBs positive was significant and our data are similar to those of Ohbayashi et al. (4) in Japan (79.9\%) and of Tong et al. (8) in members of Chinese families living in the United States compared to members living in the Orient. However, our findings are also similar to those reported by various European $(26.0-71.1 \%)(20,24)$ and American investigators $(32.0-46.0 \%)(9,22)$ regarding Western people. 
HBsAg was found in $90.0 \%$ of the mothers, $79.6 \%$ of the brothers and sisters and $37.9 \%$ of the progenies of Asian origin and, for the Western equivalents, in 30.7, 8.5 and $3.3 \%$, respectively. These differences are significant and suggest, especially for the Asian subjects, that vertical or perinatal transmission from mothers is the most important way of acquiring HBV infection, as will be seen later. These results also agree with the literature for all groups $(5,22)$.

The presence of anti-HBs, which in most cases indicates a host immune response to HBV and past infection (23), was detected in $33.9 \%$ of the members of the Asian families and in $25.8 \%$ of the members of families of Western origin. This difference was not significant, and the literature has reported the occurrence of this antibody in Asian $(5,9)$ and Western subjects $(9,20,25)$.

Anti-HBs antibodies were detected in $100 \%$ of the fathers and in $78.6 \%$ of the persons who are married to or are having an intimate (sexual) relationship with people of Asian origin. For those of Western origin, the occurrence was 40.0 and $70.0 \%$, respectively, with a significant difference between the groups of Asian and Western fathers.

It is worth emphasizing that there is no similar concomitant study with these two ethnic groups (Japanese and Western) in the literature.

In general, 41 (91.1\%) of the 45 families presented familial clustering, characterized by the existence of members (except the index case) with signs of present (HBsAg positive) or past (anti-HBs positive) infection. This clustering occurred in 94.7 and $88.5 \%$ of the Asian and Western families, respectively ( $\mathrm{P}=0.4319$; Table 2$)$. These values are higher than those reported by Bruguera et al. (20) (68.5\%) in Spain and by Szmuness et al. (9) (8.4-21.0\%) in the United States. This difference may be viewed, at least in part, as a consequence of the families submitted to different situations with the index cases, i.e., contact with chronic or acute liver disorders or healthy HBsAg carriers $(10,20,26)$.

The analysis of the HBsAg and anti-HBs markers in progenies of mothers or fathers positive for the antigen was carried out by considering all the familial possibilities; for instance, children from a genetically related relative of the index case were also included to increase the sampling for statistical analysis. The analysis of the HBV markers and of the degree of familial relation revealed that HBsAg was more frequent among genetically related individuals, whereas antiHBs was more prevalent among non-genetically related individuals (Table 5). The Asian subjects showed an alarmingly high frequency of HBsAg among genetically related relatives such as parents, brothers, sisters, children $(47.9 \%$, Table 1), as well as other genetically related members of the family (60.3\%, Table 1$)$.

The present results show that: 1) there is a high frequency of intra-familial HBV spreading, especially in families of Asian origin, and 2) applying a certain statistical methodology (12-14) allows the prediction of the frequency of HBV markers per ethnic group and per degree of familial relation. In fact, the observed values agree with the expected ones (Table 6). This is a valuable contribution of practical usefulness and, as far as we know, there is no similar report in the literature. 3) Among the families of both ethnic groups, the infected mothers are the most likely to spread HBV, a fact strongly suggesting that vertical transmission is an important way of getting the infection. On the other hand, the non-genetically related relatives presented a higher tendency to develop anti-HBs upon contact with HBsAgpositive carriers. The reason is that the contact with $\mathrm{HBV}$ is in the adult phase, when the possibility to eliminate the virus is more likely.

The present results have shown fundamental differences in the occurrence of HBsAg between families of Asian and West- 
ern origin, as also reported by others $(9,27)$. It is worth noting, however, the lack of studies including different ethnic groups from a single country. In general, studies of this kind have shown that the spreading and persistence of HBV are more efficient among Asian people than other ethnic groups $(9,28,29)$. To explain this phenomenon, hypotheses have been raised concerning environmental, nutritional and genetic factors, but they are unproved (17,30-37).

HBsAg carriers should be clinically investigated, monitored by laboratory tests and, if appropriate, submitted to a biopsy (3). The practice of these prophylactic measures including active immunization has significantly decreased the incidence of HBV infection in both Western and Asian countries $(38,39)$.

The search for other $\mathrm{HBV}$ markers (HBeAg, anti-HBe, HBsAg subtypes, and $\mathrm{HBV}$ genotyping) among the relatives of patients is currently under investigation by our group (40).

\section{Acknowledgments}

The authors thank Dr. Gabriela Ribeirodos-Santos, from Hospital das Clínicas da Faculdade de Medicina da Universidade de São Paulo, São Paulo, SP, Brazil, for critically reviewing the manuscript.

\section{References}

1. Carrilho FJ \& Corrêa MCJM (1998). Magnitude of hepatitis B and C in Latin America. In: Schinazi RF, Somadossi J-P \& Thomas HC (Editors), Therapies for Viral Hepatitis. 1st edn. International Medical Press, London, UK, 25-34.

2. EASL International Consensus Conference on Hepatitis B (2003). 13-14 September, 2002: Geneva, Switzerland. Consensus statement. Journal of Hepatology, 38: 533-540.

3. Lok AS \& McMahon BJ (2001). Chronic hepatitis B. Hepatology, 34: 1225-1241.

4. Ohbayashi A, Okochi K \& Mayumi M (1972). Familial clustering of asymptomatic carriers of Australia antigen and patients with chronic liver disease or primary liver cancer. Gastroenterology, 62: 618-625.

5. Tong MJ, Thursby MW, Lin JH et al. (1981). Studies on the maternal-infant transmission of the hepatitis B virus and HBV infection within families. Progress in Medical Virology, 27: 137-147.

6. Bosch J, Bruguera M \& Rodes J (1973). Familial spread of type-B hepatitis. Lancet, 2: 457.

7. Beasley RP, Hwang LY, Stevens CE et al. (1983). Efficacy of hepatitis $\mathrm{B}$ immune globulin for prevention of perinatal transmission of the hepatitis $B$ virus carrier state: final report of a randomized double-blind, placebo-controlled trial. Hepatology, 3: 135-141.

8. Tong MJ, Weiner JM, Ashcavai MW et al. (1979). A comparative study of hepatitis B viral markers in the family members of Asian and non-Asian patients with hepatitis B surface antigen-positive hepatocellular carcinoma and with chronic hepatitis B infection. Journal of Infectious Diseases, 140: 506-512.

9. Szmuness W, Harley EJ \& Prince AM (1975). Intrafamilial spread of asymptomatic hepatitis B. American Journal of Medical Sciences, 270: 293-304.

10. Ono-Nita SK, Carrilho FJ, Cardoso RA et al. (2004). Searching for chronic hepatitis $B$ patients in a low prevalence area - role of racial origin. BMC Family Practice, 5: 7.

11. Ratnam S \& Tobin AM (1987). Comparative evaluation of commercial enzyme immunoassay kits for detection of hepatitis B seromarkers. Journal of Clinical Microbiology, 25: 432-433.
12. Grizzle JE, Starmer CF \& Koch GG (1969). Analysis of categorical data by linear models. Biometrics, 25: 489-504.

13. Koch GG, Imrey PB, Singer JM et al. (1984). Lecture notes for analyses of categorical data. Postgraduate Course in the Department of Biostatistics. University of North Carolina Press, Chapel Hill, NC, USA.

14. SAS Institute Inc. (1985). SAS User's Guide: Statistics. 5th edn. Cary: SAS Institute, Cary, NC, USA.

15. Lok AS, Heathcote EJ \& Hoofnagle JH (2001). Management of hepatitis B: 2000 - summary of a workshop. Gastroenterology, 120: 1828-1853.

16. Conjeevaram HS \& Lok AS (2003). Management of chronic hepatitis B. Journal of Hepatology, 38 (Suppl 1): S90-S103.

17. Liaw YF, Leung N, Guan R et al. (2003). Asian-Pacific consensus statement on the management of chronic hepatitis $\mathrm{B}$ : an update. Journal of Gastroenterology and Hepatology, 18: 239-245.

18. Boss LP, Bender TR, Schreeder MT et al. (1981). Hepatitis B testing in the families and villages of five young Eskimos with primary hepatocellular carcinoma. American Journal of Epidemiology, 114: 95-101.

19. Bruguera M, Bosch J \& Rodes J (1973). Letter: Family outbreak of hepatitis B. New England Journal of Medicine, 289: 1144.

20. Bruguera M, Caballeria J, Acero D et al. (1980). Transmissión intrafamiliar del virus de la hepatitis B. Gastroenterology and Hepatology, 3: 13-18.

21. Bruguera M, Bosch J, Rodes $\mathrm{J}$ et al. (1974). Familial clustering of hepatitis B antigen: a study in relatives of patients with liver diseases and hepatitis B antigenaemia. British Medical Journal, 3: 495497.

22. Sampliner RE, Loevinger BL, Tabor $E$ et al. (1981). Intrafamilial cluster of hepatitis B virus infection: study of a large family in the United States. American Journal of Epidemiology, 113: 50-54.

23. Holland PV (1985). Hepatitis B surface antigen and antibody. In: Gerety RJ (Editor), Hepatitis B. Academic Press, Orlando, FL, USA, 5-25. 
24. Hadziyannis SJ (1975). Nonparenteral transmission of viral hepatitis in Greece. American Journal of Medical Sciences, 270: 313-318.

25. Bernier RH, Sampliner R, Gerety R et al. (1982). Hepatitis B infection in households of chronic carriers of hepatitis B surface antigen: factors associated with prevalence of infection. American Journal of Epidemiology, 116: 199-211.

26. Pastore G, Dentico P, Angarano G et al. (1981). Infectivity markers in HBsAg chronic carriers and intrafamilial spread of hepatitis $B$ virus infection. Hepatogastroenterology, 28: 20-22.

27. Derso A, Boxall EH, Tarlow MJ et al. (1978). Transmission of HBsAg from mother to infant in four ethnic groups. British Medical Journal, 1: 949-952.

28. Pongpipat D, Suvatte V \& Assateerawatts A (1980). Vertical transmission of the hepatitis B surface antigen in Thailand. Southeast Asian Journal of Tropical Medicine and Public Health, 11: 582-587.

29. Skinhoj P, Aldershvile J, Kjersem M et al. (1983). Hepatitis B infection in Vietnamese families. Journal of Medical Virology, 11: 125129.

30. Chang $\mathrm{MH}$, Hsu HC, Lee $\mathrm{CY}$ et al. (1984). Fraternal hepatocellular carcinoma in young children in two families. Cancer, 53: 1807-1810.

31. Follett EA, McMichael S, Goel KM et al. (1978). Hepatitis B in the school environment. British Medical Journal, 1: 1279-1280.

32. Helske T \& Nevanlinna HR (1973). Familial accumulation of carriers of Au antigen. Journal of Medical Genetics, 10: 270-272.
33. Kashiwagi S, Naito S, Kaneoka H et al. (1978). A family study of HBsAg carriers and major histocompatibility antigens. Fukuoka Igaku Zasshi, 69: 156-161.

34. Nasrallah SM, Nassar VH \& Shammaa MH (1978). Genetic and immunological aspects of familial chronic active hepatitis (type B). Gastroenterology, 75: 302-306.

35. Sampliner RE, Bias WB, Carney E et al. (1981). HLA antigens and HBV infection: evaluation in the chronic carrier state and in a large family. Tissue Antigens, 18: 247-251.

36. Tong MJ \& Weiner JM (1979). Lack of supportive evidence for an autosomal recessive inheritance in chronic hepatitis B infections. Digestive Diseases and Sciences, 24: 286-288.

37. Vyas GN (1974). Evidence against recessive inheritance of susceptibility to the chronic carrier state for hepatitis B antigen. Nature, 248: 159-160.

38. Lee CL \& Ko YC (1997). Hepatitis B vaccination and hepatocellular carcinoma in Taiwan. Pediatrics, 99: 351-353.

39. Beutels P, Edmunds WJ, Antonanzas F et al. (2002). Economic evaluation of vaccination programmes: a consensus statement focusing on viral hepatitis. Pharmacoeconomics, 20: 1-7.

40. Clemente CM (2003). Sequencing, genotyping and phylogenetic analysis of hepatitis B virus in Asian and Western background families of patients with chronic infection. Master's thesis, Faculdade de Medicina, Universidade de São Paulo, São Paulo, SP, Brazil. 